\title{
Gendered discursive practices on-line
}

\section{Introduction}

The use of social networking has grown exponentially into a cultural phenomenon that reaches every age demographic. One of its more curious manifestations is the proliferation of peer-to-peer on-line advice between strangers. With the world at their fingertips, increasing numbers of people are asking for, obtaining, and presumably acting upon, advice dispensed by unknown peers. This trend can be found in a wide range of areas such as travel (e.g., Tripadvisor), health (e.g., eHow) and relationships (e.g., Yahoo Answers). Given its increasing popularisation and ease of accessibility, this thriving computer-mediated discourse practice can be used to explore societal norms and expectations through the examination of authentic language usage.

This study aims to gain in-depth understanding on how (or if) asynchronous computer mediated communication (CMC), exemplified by advice giving in web-based discussion forums, is instrumental in the construction of gender identities and can thus be taken to reflect gendered discursive practices. While there is a growing body of literature on this topic, most of this work has focused on interactions in English. This paper extends the discussion into Spanish, examining mostly Argentinian websites through the systematic use of content analysis.

\section{Gender anonymity or display in cyberspace?}

Due to its wide availability and popularity across all demographics, the Internet was initially hailed as an inherently democratising medium that would enable access to all those with literacy skills and technological savvy, making social differences irrelevant or invisible on-line (Graddol \& Swann, 1989, Herring, 2000). Spears and Lea, for instance, claimed that $\mathrm{CMC}$ "can serve to reduce the social barriers to communication and thus the impact of status differentials, resulting in greater equality of participation" (1994: 428). This expectation was partly based on the absence of "gating features" (Ben-Ze'ev, 2004: 37), that is, social and physical cues as to the message sender's characteristics such as age, sex, class, physical attractiveness, or (dis)ability, that may impact interactions in face-to-face encounters. Thus early studies raised the prospect that a new gender-neutral style of interaction would typify communication on-line.

However, it is now widely recognised that a democratising technology cannot in itself guarantee social equality, nor erase social, political and cultural factors that impact on its adoption and use. One of these potentially influencing factors is gender differentiation, an important aspect of culture that is often expected to reflect in, and be constructed through, language use. Contrary to early expectations, claims of widespread gender equality have not been supported by most research on on-line interaction (Harp \& Tremayne, 2006, Herring, 2000). Indeed, a growing body of research has found that certain phenomena associated with stereotypical characterisations of gender linguistic behaviour were not diminished but actually reinforced on-line. For instance, studies have shown that women are still underrepresented in electronic bulletin boards, blogs and discussion groups, well below their proportional representations on those sites (Herring, 2004), and that in mixed-sex public discussions men still dominate interactions in terms of both quantity 
of speech and aggressiveness in responses (Herring, 1993, 2004, 2008; Selfe \& Meyer, 1991), replicating findings that have been reported for off-line interactions (Coates, 1993, Herring, 1994, West \& Zimmerman, 1983).

Herring (2000) thus pointed to an apparent paradox: that gender disparity still persists in an anonymous medium that allegedly renders sex invisible. For email communication, this can be partly explained by the tendency of most users to give off their real names in email addresses, a practice also common in blogs (Huffaker \& Calvert, 2005). But, even in the absence of clearly identifiable information such as names, nicknames or avatars, users can often signal their gender identity discursively. One explanation, consistent with self-categorisation theory (Turner et al., 1987), proposes that people internalise group prototypes and activate them when a particular category becomes germane to the interaction. Thus, gender-relevant interactions increase the salience of gender identity, and lead people to behave in a genderconsistent manner (Palomares \& Lee, 2010, Postmes \& Speares, 2002). From this perspective, participants construct and express self-designated sexual identities through gendered language usage, and thus can identify each other's genders and act accordingly; Herring (2004), for instance, describes this expected behaviour as women showing same-sex solidarity and men harassing women.

The notions that through language women exhibit same-sex solidarity and "support" whereas men harass and "control" (Fishman, 1978) or that women "rapport talk", i.e., talk to foment or enhance relationships, while men, "report talk", i.e., talk to solve problems, are among the most entrenched generalisations found in popular culture and early studies of gender and language (Tannen, 1990) Although these characterisations were proposed as applying to face-to-face communication, early scholarship on language, and gender in CMC expected that on-line interactions would report similar findings.

Yet results of on-line studies about these characterisations have been mixed. ${ }^{1}$ Some empirical studies on the use of emoticons, for instance, have supported the expectation that females use more emoticons than males in on-line messages (Witmer \& Katzman, 1997), and that in instant messaging males rarely use emoticons with other men. However, they do use them when messaging females, while females use an equal number of emoticons when interacting with both sexes (Lee, 2003). Huffaker and Calvert (2005), however, in their study of gender and language use by teenage bloggers, found that expectation challenged. Of those who used emoticons, males used more than females - not only flirtatious ones, as predicted, but also sad ones. The same study also found that, contrary to predictions, there were no clear gender differences for aggression favouring males, nor were there differences favouring females in passivity (Huffaker \& Calvert 2005). Cooperation was found across both sexes. ${ }^{2}$ Similarly, Rodino (1997) in her study of interactions in Internet Relay Chat (IRC), documented multiple and sometimes contradictory ways in which users perform gender, and suggested that binary categorisations of gendered behaviours are inadequate, as they assume gender to be an identity already pre-formed when interactions occur, rather than a performance that is accomplished through interactions

\footnotetext{
${ }^{1}$ Mixed results have also been reported in off-line interactions, but this issue reaches beyond the scope of the present paper.

${ }^{2}$ It should be noted though that, since in both instant messages and blogs personal details of the writer are on display, the results may not represent the findings in anonymous interactions.
} 
(conf. Butler, 1990). Furthermore, some recent studies have indicated a trend towards a more neutral language use in younger generations (Huffaker \& Calvert, 2005) and in large mixed groups (Baym, 1996, Herring, 2008). These contradictory findings indicate that gendered linguistic behaviour is highly context-specific, and that the context of the interaction may be more important than gender in determining linguistic behaviour (Cameron, 1992, Rodino, 1997). Thus, rather than looking for universality in behaviours, current scholarship focuses on localised instances. It examines gender and language from a perspective "that roots each in the everyday social practices of particular local communities and sees them as jointly constructed in those practices (Eckert \& McConnell-Ginet, 1992: 91)". Fruitful in examining the construction of gender through language has been the concept of Communities of Practice (CofP), defined by Eckert and McConnell-Ginet as "an aggregate of people who come together around mutual engagement in some common endeavour. Ways of doing things, ways of talking, beliefs, values, power relations - in short, practices emerge in this course of mutual endeavour" (1992:464). Participants in the present study, however, do not constitute a community in the strict sense of the term as their interactions are usually limited to a single exchange, which is insufficient to develop common practices. It is likely then that in giving advice participants are drawing on pre-existing norms of how this speech act should be expressed.

\section{The present study}

The studies considered above concern communication in English. This study seeks to extend the discussion into Spanish language, by investigating whether there is a relationship between gender and language use in a particular type of speech act online, in this case dispensing advice. Previous studies on giving advice (both on-line and off-line) have examined expert-non-expert interactions (e.g., DeCapua \& Findlay Dunham, 1993, Hudson, 1990, Locher, 2006), where issues of power, hierarchy or expertise can play a significant role in advice-givers' linguistic expressions (Vine, 2009). Peer-to-peer advice among strangers has received significantly less attention.

In the case of off-line advice, most studies have focused on how men and women interpret the functions of advice (e.g., Tannen, 1990), rather than on the linguistic realisation of the advice offered by men and women, which is the focus of this study of on-line advice. Following the discussion of on-line communication above, gender can be expected to reflect on, and be reflected in, the linguistic features of this speech act. If typical characterisations of gendered behaviour hold (e.g., Tannen 1990), it would follow that there are considerable differences between men and women in giving and receiving advice about personal problems: men would seek - and give advice to solve problems, while women would seek - and give - advice in to receive or offer empathy and/or emotional support. It would also follow that the linguistic realisation of advice may differ, with men being concise and direct and women being more emotionally expressive. Their messages would exhibit higher displays of emotional language such as greater personal disclosure, emotive features and expressions of sympathy; use of emoticons or graphical icons to represent emotions; and higher levels of indirectness to protect others' feelings. As mentioned in $\S 2$, however, some of these expectations have been challenged by recent scholarship of on-line communications in English, and so will be further investigated in the present study of Spanish on-line communications (see research questions 1 and 3). 
The anonymity of on-line communication creates the potential problem that the advice-giver's sex may be difficult to ascertain. Some user names are gender neutral, while some users prefer a photograph or avatar instead of a name in their profile, without revealing the reason for their chosen symbol. For these reasons, this study focussed on data from sources that unambiguously identified the gender of the respondent, such as messages that provided a gendered name or nickname, or explicitly showed gender orientation through the use of pronouns or adjectives (e.g., nosotras siempre sabemos "we [fem.] always know...", estoy harta 'I'm sick and tired $[\mathrm{fem}].)^{3}$ when investigating advice-offers produced by males or females.

One less explored issue in the area of gender and advice is the potential effect of the sex of the advice-seeker on the structure and content of the message. Unlike advicegivers, advice-seekers unambiguously reveal their sex while explaining their problems and through their signature, while typically omitting other personal information or identifying features. Sex is thus the interlocutor's only identifiable variable. This factor has received little attention in the literature. One notable exception is Mattheson (1991), who examined how social perceptions during CMC are influenced by the availability of social information about participants in the communication and are based on participants' internalised social expectations. When told that their interlocutors were females, participants expected more cooperative behaviours than when no clues about the interlocutor's sex were given, indicating that information about the interlocutor's sex may trigger internalised stereotypes and expectations in other participants. The present study seeks to contribute epistemically to this area through an examination of the effect of the sex of on-line interlocutors on the formulation of advice given to them, that is, how men and women are given advice not just how they produce advice - in terms of directness and politeness (see research question 2 below).

The following research questions guided this study's enquiry into gender and CMC in Spanish language:

Research Question 1: Is there a relationship between the sex of advice-givers and the linguistic realisation of their advice offers vis a vis the perceived sex of the advice- seeker?

Research Question 2: Is there a relationship between the sex of advicereceivers and the linguistic realisation of advice offers they receive?

Research Question 3: Do advice-givers conform to expected responses displaying emotional expression for females, and lacking emotion for males regardless of the gender of advice-receivers, or are advice-givers' behaviours affected by sex information about their interlocutors?

\subsection{Methodological approach}

\footnotetext{
${ }^{3}$ Admittedly, there is still a possibility that, even in these cases, advice-givers could be crossing gender. This is an unavoidable problem. However, in case of deception, writers choose to position themselves as members of a particular gender thus can be expected to have adopted what they consider as gender consistent linguistic behaviour. This was deemed sufficient for the purpose of the study.
} 
The study centred on empirical analysis of a small corpus of on-line advice. Internet research has many advantages over other methods: (1) it allows direct access to data from authentic interactions without the researcher potentially influencing results or biasing the data collection processes; (2) since the data, although written, also exhibits features of spoken language (Soffer, 2010, Yates, 1996, Yus, 2010), researchers can tap into what speakers actually say or write rather than speculate about or infer from speakers' intuitions or knowledge of prescribed norms, which are not always reliable indicators of behaviour; (3) it can yield a large number of linguistic tokens that can be used easily to create a corpus without the time and effort involved in transcribing oral interactions. The data collected was analysed through web content analysis (Herring, 2010), a method well suited to systematically explore the quality and quantity of particular properties of the language used on-line.

\subsection{Procedure}

Consistent with most current work in this area (e.g. DeCapua \& Findlay Dunham, 2007, Eisenchlas, 2011, Locher, 2006), this study's approach to on-line advice-giving assumes that advice is generally embedded within other discursive moves. These moves typically function as means to frame the advice in such a way that makes it acceptable to the advice-seeker. Therefore, to address the first research question that examines the linguistic realisation of advice, the first step in the analysis was to identify and quantify the varied discursive moves found in the corpus. The moves frequently identified in the literature include: (1) bold advice , (2) assessment, described as "a passage in which the advice seeker's particular situation is mentioned and evaluated" (Locher, 2006: 63), (3) elaboration, i.e., an explanation of a point just made, (4) mentioning shared experiences as a means to establish solidarity or showing empathy with the advice seeker, (5) discussing one's own experiences as a way to establish the respondent's suitability to offer advice, (6) expressing empathy, which includes using nicknames, greetings and farewells, encouraging expressions, offers of additional help, use of inclusive second person plural pronouns, and use of emoticons, (7) disclaimers, that is, admissions that the respondent is not able or qualified to offer advice, and (8) referrals to professional help. Previous offline research findings predict suggest great variation to be found in the distribution of discursive moves as a factor of the sex of advice-givers and receivers. This paper explores whether the results obtained from our study support or challenge the expectation that women offer more frequent tokens of sympathy and emotional support than their male counterparts (question 3).

The second step in our analysis involved separating advice tokens from the other moves mentioned above. A post was treated as advice if the respondent used: (1) explicitly marked recommendations (yo te aconsejo que hables con ella sobre su relacion y lo que no esta funcionando ${ }^{4}$ 'I advise you to talk to her about your relationship and what is not working'); (2) imperatives or subjunctives following negation (Dale tiempo 'Give her time'; No te engañes más Brad Pitt 'Do not deceive yourself any longer, Brad Pitt'); (3) modal verbs of obligation (Tenes que estar seguro de eso 'You have to be sure of that'); (4) value judgement or impersonal expressions (Es mas facil dejar una relacion en menor tiempo posible 'It is easier to leave a

\footnotetext{
${ }^{4}$ Data are presented as written by the contributors, without editing the syntax or orthography. The only change is the Italianisation of the Spanish examples. Case was kept as in the original text.
} 
relationship as soon as possible'); or where (5) the response conveyed a personal experience that offered an implicit but unambiguous suggestion on a course of action to take. Previous studies (e.g., Locher, 2006; Eisenchlas, 2011) have reported that [advice-givers' responses typically contain a number of advisory tokens. Each token was treated as a unit of analysis. The advice tokens were further coded and tagged according to their syntactic realisation into (1) declaratives; (2) directives; (3) interrogative phrases; and (4) non-verbal or non-finite constructions. Examples of each type are shown in Table 1. As can be seen in the table, directives and declarative tokens include a number of subcategories.

Table 1: Syntactic realisation of advice offers on-line

\begin{tabular}{|c|c|c|}
\hline Type & Spanish example & English translation \\
\hline (1) Declaratives & & \\
\hline $\begin{array}{l}\text { a. Present tense } \\
\text { marked }\end{array}$ & $\begin{array}{l}\text { Mi consejo es que hables } \\
\text { con la persona que la trata }\end{array}$ & $\begin{array}{l}\text { My advice is that you talk } \\
\text { to the person who treats } \\
\text { her }\end{array}$ \\
\hline $\begin{array}{l}\text { b. Present tense (with } \\
\text { modal verbs) }\end{array}$ & $\begin{array}{l}\text { yo te digo q tenes q no } \\
\text { hablarle }\end{array}$ & $\begin{array}{l}\text { I'm telling you that you } \\
\text { need to not talk to her }\end{array}$ \\
\hline $\begin{array}{l}\text { c. Present tense with } \\
\text { imperative force }\end{array}$ & Vas y le decis & You go and you tell her \\
\hline d. Future & $\begin{array}{l}\text { podrás intentar atenuar ese } \\
\text { dolor, si al dejarla le } \\
\text { explicas tus motives }\end{array}$ & $\begin{array}{l}\text { You will try to alleviate } \\
\text { that pain if, when you } \\
\text { leave her, you explain your } \\
\text { reasons }\end{array}$ \\
\hline e. Conditional & $\begin{array}{l}\text { Tendrias que respetarte a ti } \\
\text { mismo }\end{array}$ & $\begin{array}{l}\text { You would have to respect } \\
\text { yourself }\end{array}$ \\
\hline $\begin{array}{l}\text { f. Present tense } \\
\text { evaluations/ }\end{array}$ & $\begin{array}{l}\text { es mas facil dejar una } \\
\text { relacion en menor tiempo } \\
\text { possible }\end{array}$ & $\begin{array}{l}\text { it's easier to leave a } \\
\text { relationship as soon as } \\
\text { possible }\end{array}$ \\
\hline $\begin{array}{l}\text { Impersonal } \\
\text { expressions }\end{array}$ & $\begin{array}{l}\text { hay que actuar con un } \\
\text { poco de frialdad }\end{array}$ & one must act a bit cool \\
\hline $\begin{array}{l}\text { g. Subjunctive } \\
\text { without } \\
\text { subordinator }\end{array}$ & que no te descubran & $\begin{array}{l}\text { that they don't discover } \\
\text { you }\end{array}$ \\
\hline $\begin{array}{l}\text { (2) Directives } \\
\text { a. Imperative }\end{array}$ & Dale tiempo & Give him time \\
\hline $\begin{array}{l}\text { b. Subjunctive } \\
\text { following negation }\end{array}$ & $\begin{array}{l}\text { No te engañes más Brad } \\
\text { Pitt }\end{array}$ & $\begin{array}{l}\text { Don't fool yourself any } \\
\text { longer Brad Pitt }\end{array}$ \\
\hline
\end{tabular}




\begin{tabular}{|l|l|l|}
\hline (3) Interrogatives & $\begin{array}{l}\text { Por q no hablas con la } \\
\text { familia y listo }\end{array}$ & $\begin{array}{l}\text { Why don't you talk to the } \\
\text { family and that's it }\end{array}$ \\
\hline $\begin{array}{c}\text { (4) Non-verbal/non-finite } \\
\text { constructions }\end{array}$ & basta de dar vueltas! & Enough spinning around! \\
\hline
\end{tabular}

The next step involved systematically coding and quantifying the frequency distribution of the different constructions (i.e., declaratives, directives, interrogatives, and non-verbal or non-finite constructions) and the sex of both advice seeker and advice-giver. This allowed for the study of patterned ways in which speakers use the grammatical resources of the language under investigation, namely, Spanish.

Finally, a statistical analysis was conducted on the units of advice. A total of eight measures of structure related advice (four to male advice seekers, four to female advice seekers) were examined in terms of the extent to which the frequency of these categories of advice differed when given by male vs. female advice-givers. Participants' advice was reported in terms of sex of advice-giver and frequency of advice-giving per sex of advisee. The effect of sex of participant on each of the eight measures of advice structure was further examined via the Kruskal-Wallis (KW) test, a nonparametric equivalent of ANOVA.

\subsection{The data}

The corpus of advice offers analysed in this paper was collated from responses to 17 questions posted by males and females in 2008-2009 on eight public web-based Spanish language sites (Appendix 1 lists the websites consulted). The questions asked for advice on how to break up with a boyfriend or girlfriend without hurting their feelings. A total of 260 posts were obtained from 185 contributors. One hundred and ninety six of the posts indicated the sex of their contributor - 100 from males and 96 from females - while for the remaining 64 posts the contributor's sex was unspecified and the posts were thus disregarded in the analysis.

The vast bulk of posts included in the analysis $(n=196)$ were treated as advice on the basic criteria listed above. Following these criteria, responses that were limited to sharing an experience and did not propose a solution, or that focussed on criticising or even abusing - the advice seeker, did not qualify as advice. Although such responses were not included in the tokens of advice, they were nonetheless classified as 'non-advice responses' and included in the discussion, as they showed interesting tokens of emotional expression across sexes (question 3). Sixteen responses were included in this category.

All websites used, except for Yahoo Mexico and Vogue España, were from Argentina, as the list of sites in Appendix 1 reveals. However, the respondents' backgrounds varied more than the list suggests due to the global accessibility that the Internet affords. This was evident in the respondents' use of regionalisms that are not typical of Argentinian Spanish, and that could not be identified in many instances. For this reason, respondents' geographical backgrounds, which could have yielded crossdialectal differences, were ignored in this study. 


\section{Results}

\subsection{Syntactic units}

Responses typically contained from one to seven units of advice, and thus the 196 responses classed as advice yielded a total of 639 advice units (means $=3.2$ per response). Of these, 344 (54 per cent) were produced by males, 295 (46 per cent) by females. Table 2 displays the results for syntactic formula in on-line advice data.

Table 2: Distribution of syntactic formula in on-line data $(n=639)$

\begin{tabular}{|l|l|l|l|}
\hline Imperatives & Declaratives & Non-verbal/non-finite & Interrogatives \\
\hline $453(71 \%)$ & $159(24 \%)$ & $23(4 \%)$ & $4(1 \%)$ \\
\hline
\end{tabular}

The most striking finding is the low frequency of declarative sentences (one subtype of which would be marked sentences containing a subjunctive clause following advice verbs) and the high frequency of directives, typically associated with the imperative mood. Interrogative sentences and non-verbal/non-finite constructions were used very infrequently and therefore will not be discussed further.

Further examination of the data reveals the wide range of formulas used in the on-line advice. As for directives, the majority of expressions were 'positive commands' (i.e., expressed through the imperative mood), maybe reflecting a tendency by respondents to give advice-seekers positive measures to adopt rather than advice on what to avoid. The second most frequent strategy is represented by the so-called 'negative commands' (i.e., which in Spanish are expressed by subjunctives following negation). Modal verbs of obligation were not frequent in the data, and were expressed mostly as positive commands. The distribution of directives is given in Table 3.

Table 3: Distribution of imperatives in on-line data $(n=453)$

\begin{tabular}{|l|l|l|}
\hline Positive & Negative & Modal verbs \\
\hline $348(54 \%)^{5}$ & $75(12 \%)$ & $\begin{array}{r}30(5 \%) \\
\text { - } 26 \text { positive } \\
\end{array}$ \\
& & 4 negative \\
\hline
\end{tabular}

Declarative sentences showed a wide range of patterns, as can be seen in Table 4. However, the distribution of these advice patterns, with the exception of impersonal and value judgement expressions, was extremely low. Interestingly, performative verbs of advice followed by subjunctives, the pattern presented as the canonical advice structure in grammar books, accounts for only 5 per cent of the total units of on-line advice, followed closely by the conditional and modal verbs. Finally, present and future verbs with imperative force were infrequent but valid options in the on-line data.

\footnotetext{
${ }^{5}$ Percentages were obtained by dividing the number of tokens of particular structures by the number of advice units (i.e. $\mathrm{n}=639$ )
} 
Table 4: Distribution of declaratives in on-line data $(n=159)$

\begin{tabular}{|l|l|l|l|l|l|l|}
\hline $\begin{array}{l}\text { Impersonal } \\
+ \text { Present } \\
\text { tense } \\
\text { evaluations }\end{array}$ & $\begin{array}{l}\text { Present }+ \\
\text { Subordinated } \\
\text { clause }\end{array}$ & Conditional & $\begin{array}{l}\text { Present } \\
\text { w/imper. } \\
\text { force }\end{array}$ & $\begin{array}{l}\text { Present } \\
+ \text { modal } \\
\text { verb }\end{array}$ & $\begin{array}{l}\text { Subjunctives } \\
\text { in } \\
\text { independent } \\
\text { clauses }\end{array}$ & Future \\
\hline $61(10 \%)$ & $32(5 \%)$ & $22(3 \%)$ & $19(3 \%)$ & $12(2 \%)$ & $9(1 \%)$ & $4(0.5 \%)$ \\
\hline
\end{tabular}

The tables above summarise the overall distribution of syntactic structures that Spanish-speaking participants used on-line for giving advice to unknown peers. To examine whether the sex of advice-givers (research question 1) and/or the sex of advice-seekers (research question 2) influences the syntactic realisation of advice, a Kruskal-Wallis (KW) test was conducted on the data. The results are shown in Figure 1 .

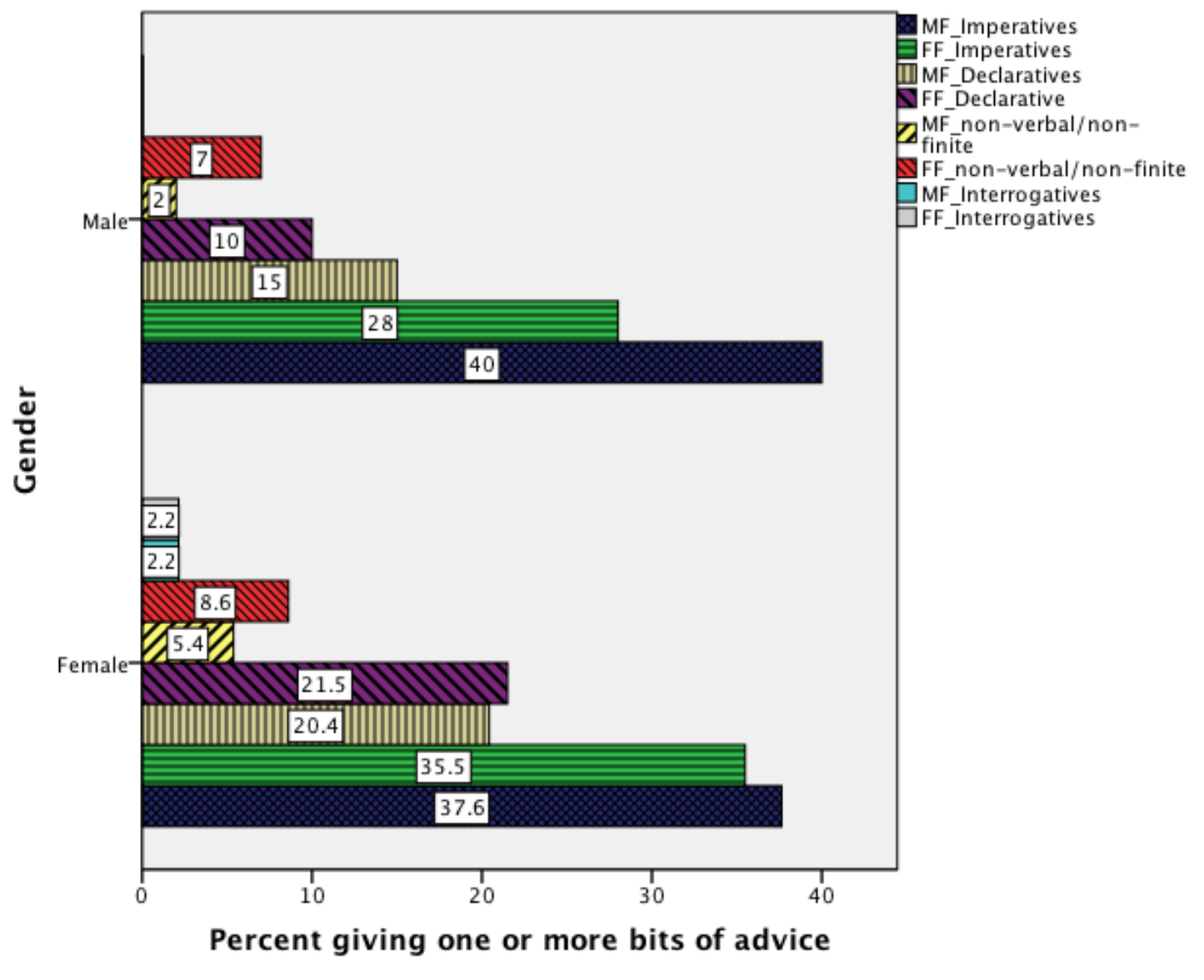

Figure 1 Percent of males or females giving one or more bits of structure-related advice to male or female advice-seekers 
The examination of frequencies and percentages per strategy category reveals some interesting trends. It was expected that, if women are more polite and concerned about protecting others' feelings, expression in their posts would be less direct. However, this expectation was not met. Consistent with the overall distribution of syntactic structures (summarised in Table 2), both males and females exhibited very high frequency in their use of directives. While males were most likely to use directives when advising males (40 per cent), and females were most likely to do so when advising females (37.6 per cent), these disparities were not statistically significant. A comparison between the types of directive used (i.e., positive versus negative commands) similarly reveals no statistically significant differences. Both sexes were very direct in the advice they dispensed to both males and females. In addition, both used a wide range of attenuating elements to soften the force of their advice, such as elaborations, expressions of empathy, use of nicknames, adulation, expressions of affection and encouragement, and emoticons, as discussed below when dealing with research question 3 .

The only statistically significant difference across sexes concerning syntactic structure relates to declarative sentences. Based on Kruskal-Wallis tests, females were significantly more likely than males to use declaratives when providing advice to females, but not to males $\left(\chi^{2}=4.540(1), p<.05\right)$. However, further analysis reveals that this difference between sexes was restricted to present tense evaluations, with all other subtypes showing statistically comparable results.

\subsection{Other moves}

To address research question 3, i.e., whether the sex of advice-givers conforms to the expectation that females display emotional expression when offering advice, and males generally do not, a descriptive analysis was conducted on other advice related moves: elaborations and assessments, amount of personal disclosure, and expressions of affect. Given the limited tokens, statistical analyses were not conducted on personal disclosure and affect expressions.

\subsubsection{Elaborations and assessments}

A further comparison was made with regard to assessments and elaborations used by both sexes when providing advice. It was expected that in keeping with stereotypical beliefs about gendered linguistic behaviour, males would predominantly give bold and concise advice, while females would display greater use of rhetorical devices and thus their posts would be longer, particularly when giving advice to other females. These expectations were not met. While female-to-male advice was significantly longer than other posts (average 103.5 words per post), there were no significant differences between the other responses ( $\mathrm{F}$ to $\mathrm{F} 56.86$ words per post; $\mathrm{M}$ to $\mathrm{M} 64.17$ words; $\mathrm{M}$ to F 52.61 words). Female to female posts included statistically significant differences in

the number of elaborations $\left(\chi^{2}=3.973(1), p<.05\right)$, but no other significant differences were found between the tokens of elaboration and assessment across sexes. Both males and females assessed the situations and justified the advice they dispensed to male and female advice-seekers and bold advice was infrequent in the data. 


\subsubsection{Shared personal experiences}

The data revealed that offering shared experiences was a frequent move by advicegivers, either as a means to establish solidarity or empathy with the advice-seeker, or to establish the respondent's suitability to offer advice. Drawing on stereotypical beliefs about gendered interactions, it was expected that females would share experiences and disclose personal information more readily than males. It was further expected that more personal stories would be shared with females than males, as females are typically viewed as relationship experts. Yet, these expectations were not met. Of the 47 instances of personal experiences shared by advice-givers, 23 were produced by females and 24 by males. Interestingly, both males and females seemed more ready to share experiences with males, who received 35 (74 per cent) of the experience-sharing responses.

Further evidence of this trend can be found in posts excluded from previous analyses and classified as 'non-advice'. Of the 16 posts excluded, nine were instances of respondents expressing inability to offer advice but willingness to share experiences, past or present, with the advice-seekers. Of these nine, five were produced by males and 4 by females, but eight were directed at males.

\subsubsection{Affect display}

Consistent with stereotypical characterisations of how displays of affect are gendered, it was expected that women would be more emotionally expressive than males, and thus their messages would exhibit greater expressions of empathy and sympathy. Expressions of sympathy on-line involve using nicknames, greetings and farewells, tokens of encouragement, offers of additional help, use of second person plural pronouns, and use of emoticons and graphical icons to represent emotions. On the other hand, since anger is believed to be more characteristic of males (Brody, 1997, Hutson-Comeaux \& Kelly, 2002) it was expected that males would produce more tokens of abuse or flaming. Also, given the historical imbalance of power between men and women, more sexist remarks were expected from male than from female respondents. These expectations were only partly met. I examine the use of some of these devices in the following discussion.

\subsubsection{Nicknames}

Nicknames can be defined as informal names given to individuals in place of their given names. While being humorous or affectionate, nicknames can also be disparaging, but very few of the nicknames found in the data were derogatory. Since participants do not know each other, using an affectionate nickname to refer to the addressee can be seen as either an attempt to establish solidarity and show empathy, or as an unwarranted - thus unwelcome - act of familiarity. The expectation that females would establish solidarity with other females was not met. 35 nicknames were used, of which 31 were by males and only 4 by females. More remarkable is that males used nicknames predominantly to address other males $(n=27)$ and used only four to address females. Although we can only speculate as to the reasons for this disparity, it may be that men did not want to display attitudes that could be seen as flirtatious. That the nicknames were used in attempts to establish solidarity with the addressee is evident in the nicknames used. The most frequent were amigo 'friend' 
and its variants (e.g., compañero 'mate', camarada 'comrade') ( $\mathrm{n}=10)$; flaco (lit. skinny), loco (lit. crazy), chavón, compadrito, pibe, all roughly equivalent to 'dude' $(\mathrm{n}=10)$; family terms (papa 'dad', hermano 'brother') $(\mathrm{n}=2)$; and references to masculinity (varón, macho) $(\mathrm{n}=2)$. There were only two female uses of nicknames for males (niño, nene 'boy') which sound derogatory and infantilising.

\subsubsection{Text based and graphical emoticons}

A total of 34 emoticons were found in the posts, including four text based and 30 graphic. The most frequently used emoticon was the graphical smiley (:) $^{6}(n=9)$, followed by thumbs up $(n=7)$. Most of the graphic emoticons displayed positive messages, except for the angry $(n=3), \operatorname{sad} 8(n=2)$ and sarcastic $(n=2)$ tokens. No flirtatious emoticons were found in the data.

Table 5 shows the number of emoticons used as a factor of sex of the user and receiver.

Table 5: Text based and graphic emoticons

\begin{tabular}{|l|l|l|l|}
\hline & \multicolumn{2}{|c|}{ Advice Seeker } & \\
\hline Advice giver & $\mathrm{M}$ & $\mathrm{F}$ & Total \\
\hline $\mathrm{M}$ & 6 & 18 & 24 \\
\hline $\mathrm{F}$ & 5 & 5 & 10 \\
\hline & 11 & 23 & 34 \\
\hline
\end{tabular}

As the table reveals, despite expectations to the contrary and consistent with Huffaker and Calvert's (2005) findings, male respondents displayed more graphic expressions of emotions than females. Moreover, while no differences were found in female use of emoticons according to the sex of the addressee, males used significantly more emoticons when advising females than when advising males.

\subsubsection{Humour}

These data reveal the use of humour mostly as a mitigating device. In the posts examined, humour remains a male domain. All up there were 24 tokens of humour, mostly indicated by text-based expressions of laughter (jajaja or jeje; $\mathrm{n}=13$ ), a joke $(n=6)$ or graphic emoticons $(n=5)$. All except one appeared in posts made by males, 14 directed at males and 10 at females. Consistent with the stereotype claiming females don't understand jokes, jokes were reserved for male addressees, and the only expressions of humour directed at females were graphic representations of laughter.

\subsubsection{Greetings, farewells and encouragement}

Greetings were not frequent $(\mathrm{n}=11)$ and were evenly distributed across sexes for giving and receiving advice, while males producing five tokens and females produced six. Much more common were farewells and expressions of encouragement. Many advice-givers ended their posts by wishing the advice-seeker good luck, or expressing hope that the advice they dispensed was useful or that the advice seeker feels happier soon. Expressions of affection towards unknown advice-seekers were also frequent

\footnotetext{
${ }^{6}$ This classification is based on: http://messenger.msn.com/Resource/Emoticons.aspx
} 
(e.g., un abrazo gigante 'a giant hug', un besito 'a small kiss', un besote 'a big kiss'), as were positive evaluations of the advice-seeker and promises that the advice given will work. Greetings and farewell were grouped together because at times these could not be clearly separated; some expressions can serve both functions (e.g., suerte 'good luck'). Table 6 shows the combined tokens of farewells and encouragement as a function of sex.

Table 6: Farewells and encouragement

\begin{tabular}{|l|l|l|l|}
\hline & \multicolumn{2}{|c|}{ Advice Seeker } & \\
\hline Advice giver & $\mathrm{M}$ & $\mathrm{F}$ & Total \\
\hline $\mathrm{M}$ & 28 & 28 & 56 \\
\hline $\mathrm{F}$ & 29 & 30 & 59 \\
\hline & 57 & 58 & 115 \\
\hline
\end{tabular}

As can be seen from the table, there were virtually no differences in the number of farewell and encouragement tokens across sexes of advice-givers and receivers.

\subsubsection{Abuse and sexist statements}

Consistent with findings in previous studies (Herring, 1993, Herring, 2004, Selfe \& Meyer, 1991), most of the abusive responses were in posts by males. A post was deemed as 'abusive' if it contained an insulting or derogatory evaluation of the advice-seeker or their partner. Overall, there were 24 tokens of abuse in the responses (including non-advice responses); some directed at the partner of the advice-seeker, some at the advice-seekers themselves. Most abusive responses were produced by males $(n=17)$ rather than females $(n=7)$, and most were directed at males $(n=17)$ rather than at females $(n=7)$.

Similarly, most instances of sexist statements, taken in this paper to mean any broad generalisation based merely on sex, ${ }^{7}$ were found in male responses $(n=15)$ rather than in female posts $(n=5)$. Unlike the tokens of abuse, the sexist statements were mostly directed at females $(\mathrm{n}=11)$, whereas females' sexist remarks were produced as a response to males' sexist comments.

\section{Discussion and conclusion}

The main goal of this study was to explore how one particular speech act, namely, advice giving, is realised on-line in Spanish language forums, focusing in particular on the effect of the participant's sex on the linguistic realisation of the message. Three research questions were formulated to this end, The first two investigated potential differences in the syntactic structure of advice on the basis of the sex of the advicegiver (research question 1), and/or the sex of the advice-seeker (research question 2). The third question examined whether the sex of advice-givers conforms to the expected display of emotional expression in females' responses posts, and lack of emotion in males' posts.

\footnotetext{
${ }^{7}$ As Mills (2008) remarks, there is no consensus as to what constitutes sexism. Feminist scholars have argued that, for a comment to be sexist, it has to be directed at members of a minority group (i.e., women). This would preclude men from being targets of sexism. This proviso is acknowledged in the expectation that females are more frequent recipients of sexist comments than males (see §4.4.3). But in classifying the data I have taken a broader view.
} 
On question 1, no significant differences were found in the tokens of advice dispensed by males and females. While subjunctives following marked verbs of advice are typically associated with expressions of pragmatic courtesy, the data showed that both males and females were very direct in their advice, favouring bald directives over all other possible linguistic expressions. Even so, they used a wide range of mitigating devices - expressions of empathy, adulation, affection and encouragement, as well as nicknames and emoticons - to soften the force of directives. Briz (2002) suggests that in Spanish conversations, mitigation is used as a strategic resource to seek the acceptance of the listener, through either the message or the speaker him/herself, and thus relates to establishing face. As the data show, this conversational feature was also prevalent in on-line interactions.

Elaborating or giving reasons for the advice also act as mitigating procedures. Yet this was another area where no significant differences were found across sexes. Men gave reasons for the advice they offered as frequently as women did, even though men choose bald directives to formulate their advice.

The frequent use of directives revealed in the data may be explained partly by the nature of on-line communication, which invites a less formal mode of interaction. A number of studies have noted that the language used on the internet tends to be short and concise, and typically favours syntactically simple and direct messages. It may well be that in advice situations, where the advice-seeker and giver do not know each other, hierarchy considerations are less relevant to both parties. Someone requesting advice may appear to be placing the advice-giver in the 'expert role', but the anonymity of all participants and the lack of follow-up in the interaction means that the advice-seeker is not compelled to accept the advice offered nor to have any relationship whatsoever with the advice-giver, and therefore issues of face play a smaller role than in face to face encounters. Moreover, the elicited nature of advice may have an impact in its linguistic realisation. In a study of directives in the workplace, Vine (2009) observed that the use of imperatives is frequent when a directive is elicited directly, such as in problem-solving interactions. Perhaps the elicited nature of the advice, the lack of continuity in the interaction and the impossibility of the advice recipient asking for clarification bring other pragmatic principles into play, related to the relevance, clarity and economy of the message (cf. Blum-Kulka, 1987).

As to question 2, the data showed no significant difference in the syntactic realisation of advice as a function of the sex of the advice seeker. Males and females were equally forward and direct when dispensing advice to either sex. What is remarkable in the data is that most respondents offered advice and seemed genuinely interested in helping advice seekers, regardless of sex, at times offering additional assistance such as adding a phone number in case the advice seeker needed to discuss the situation further. The expectation that men would receive more direct advice from males and that women would receive more offers of emotional support from females was not met in the on-line data.

Question 3 empirically tested the expectation that females would be more likely than males to display emotion in their posts, except perhaps for anger which is traditionally seen as a male domain. This expectation was only partly met. Some areas, such as the use of greetings, farewells and encouragements, which can be seen as expressions of 
sympathy, revealed no significant differences across sexes. Similarly, both males and females shared life experiences and disclosed personal and at times painful information, interestingly more so in posts directed to males than to females. As expected, however, tokens of sexism, abuse and flaming were typically restricted to posts made by males, as were tokens of humour. But contrary to expectations, while females produced many of the expected affect displays, men were equally prone to express emotion on-line, at times producing more emotional tokens than females did, and not just with other males but in their responses to females as well. This can be seen in the use of emoticons (consistent with the findings of Huffaker \& Calvert (2005) but contrary to those of Witmer \& Katzman (1997) and Lee (2003), and in the extensive use of affectionate nicknames used to address other males.

The findings that emerge from analysis of the data point to a more complex picture than the stereotypically binary characterisation of female versus male behaviour would lead us to expect. If gendered differentiation is reflected in language use, marked differences in the language used on-line by males and females, as identified in previous research (Herring, 1993 and subsequent work, Selfe \& Meyer, 1991) would have been expected. This expectation was not met. A few factors may explain the disparity of the findings.

First, language and culture may play a role. Most of the previous studies analysed interactions in English, which may explain different linguistic practices across sexes. Spanish speaking cultures are frequently categorised as being sexist, but what this characterisation entails - if a whole culture can be possibly summed up with a single adjective - is a matter for further debate and empirical investigation. Second, many previous studies have focused on electronic bulletin boards, blogs and discussion groups. Most (all?) of these sites are not anonymous and participants get to know one another. More importantly, most of these interactions involve continuity in time, which in turn results in the development of communities of sorts with their own rules - or the rules that operate in society at large. The data examined in this paper, on the other hand, were collated from sites where the interaction between participants is a one-off event and where the advice-seeker needs a quick fix to a problem, thus the "polite" response is a clear and direct one, regardless of sex. A final consideration relates to the characteristics of the communication medium. While sexism, abusive behaviour and more generally flaming have been attributed to the anonymity of online interactions, it may be precisely this feature that also allows men to 'open up' and be more forward in expressing affect.

The intact sample on which this naturalistic study was based is small. Even so, it still pointed to some interesting trends. In particular, it challenged the claim that the use of language on the internet leaves no doubt as to writers' sex. Whether differences obtain across types of sites, languages, cultures, topics and tasks are issues that deserve further investigation. 


\section{References}

Baym, N. 1996. Agreements and disagreements in a computer-mediated discussion. Research on Language and Social Interaction 29:315-345.

Ben-Ze'ev, A. 2004. Love Online: Emotions on the Internet. Cambridge: Cambridge University Press.

Blum-Kulka, S. 1987. Indirectness and politeness in requests: Same or different? Journal of Pragmatics 11:131-146.

Briz, A. 2002. La estrategia atenuadora en la conversación cotidiana española. Paper presented at Primer coloquio del programa EDICE, Stockholm.

Brody, L.R. 1997. Gender and emotion: Beyond stereotypes. Journal of Social Issues 53:369-394.

Butler, J. 1990. Gender Trouble: Feminism and the Subversion of Identity. New York: Routledge.

Cameron, D. 1992. Feminism \& Linguistic Theory. New York: St. Martin's Press.

Coates, J. 1993. Women, Men and Language: A Sociolinguistic account of gender differences in language: Longman.

DeCapua, A., and Findlay Dunham, J. 1993. Strategies in the discourse of advice. Journal of Pragmatics 20:519-531.

DeCapua, A., and Findlay Dunham, J. 2007. The pragmatics of advice giving: Crosscultural perspectives. Intercultural Pragmatics 4:319-342.

Eckert, P., and McConnell-Ginet, S. 1992. Communities of practice: Where language, gender, and power all live. In Locating Power: Proceedings of the Second Berkeley Women and Language Conference, eds. Kira Hall, Mary Bucholtz and Birch Moonwomon, 89-99. Berkeley, Calif.: Women and Language Group.

Eisenchlas, S.A. 2011. On-line interactions as a resource to raise pragmatic awareness. Journal of Pragmatics 43:51-61.

Fishman, P. 1978. Interaction: The work women do. Social Problem 24:397-406.

Graddol, D., and Swann, J. 1989. Gender Voices. Oxford, UK ; Cambridge, MA: Blackwell.

Harp, D., and Tremayne, M. 2006. The gendered blogosphere: Examining inequality using network and feminist theory. Journalism \& Mass Communication Quarterly 82:247-264. 
Herring, S.C. 1993. Gender and democracy in computer-mediated communication. Electronic Journal of Communication 3.

Herring, S.C. 1994. Politeness in computer culture: Why women thank and men flame. In Cultural Performances: Proceedings of the Third Berkeley Women and Language Conference, eds. M. Bucholtz, A. Liang and L. Sutton, 278294. Berkeley: Berkeley Women and Language Group.

Herring, S.C. 2000. Gender differences in CMC: Findings and implications. In CPSR Newsletter.

Herring, S.C. 2004. Computer-mediated communication and Woman's Place. In Language and Woman's Place: Text and Commentaries, ed. M. Bucholtz, 216222. New York ; Oxford: Oxford University Press.

Herring, S.C. 2008. Gender and power in on-line communication. In The Handbook of Language and Gender, eds. J. Holmes and M. Meyerhoff. Oxford, UK: Blackwell Publishing Ltd.

Herring, S.C. 2010. Web content analysis: Expanding the paradigm. In The International Handbook of Internet Research, eds. J. Hunsinger, M. Allen and L. Klastrup, 233-249. Berlin: Springer Verlag.

Hudson, T. 1990. The discourse of advice giving in English: 'I wouldn't feed till Spring no matter what you do.' Language and Communication 10:285-297.

Huffaker, D.A., and Calvert, S.L. 2005. Gender, identity, and language use in teenage blogs. In Journal of Computer-Mediated Communication.

Hutson-Comeaux, S.L., and Kelly, J.R. 2002. Gender stereotypes of emotional reactions: How we judge an emotion as valid. Sex Roles 47:1-10.

Lee, C. 2003. How does instant messaging affect interaction between the genders? In The Mercury Project for Instant Messaging Studies at Stanford University.

Locher, M.A. 2006. Advice Online: Advice-giving in an American Internet Health Column. Amsterdam/Philadelphia: John Benjamins.

Mattheson, K. 1991. Social cues in computer-mediated negotiations: Gender makes a difference. Computers in Human Behavior 7:137-145.

Palomares, N.A., and Lee, E.-J. 2010. Virtual gender identity: The linguistic assimilation to gendered abatars in computer-mediated communication. Journal of Language and Social Psychology 29:5-23.

Postmes, T., and Speares, R. 2002. Behavior online: Does anonymous computer communication reduce gender inequality? Personality and Social Psychology Bulletin 28:1073-1083. 
Rodino, M. 1997. Breaking out of Binaries: Reconceptualizing Gender and its Relationship to Language in Computer-Mediated Communication. Journal of Computer-Mediated Communication Quarterly [Online] 3:available:[http://jcmc.indiana.edu/vol3/issue3/rodino.html].

Selfe, C.L., and Meyer, P.R. 1991. Testing claims for on-line conferences. Written Communication 8:163-192.

Soffer, O. 2010. "Silent orality": Toward a conceptualization of the digital oral features in CMC and SMS texts. Communication Theory 20:387-404.

Spears, R., and Lea, M. 1994. Panacea or panopticon? The hidden power in computermediated communication. Communication Research 21:427-459.

Tannen, D. 1990. You Just Don't Understand: Women and Men in Conversation. New York: William Morrow.

Turner, J.C., Hogg, M.A., Oakes, P.J., Reicher, S.D., and Wetherell, M.S. 1987. Rediscovering the Social Group: A Self-Categorization Theory. New York: Basil Blackwell.

Vine, B. 2009. Directives at work: Exploring the contextual complexity of workplace directives. Journal of Pragmatics 41:1395-1405.

West, C., and Zimmerman, D.H. 1983. Small insults: A study of interruptions in cross-sex conversations between unacquainted persons. In Language, Gender and Society, eds. B. Thorne, C. Kramarae and N. Henley, 102-117. Cambridge: Newbury House.

Witmer, D.F., and Katzman, S.L. 1997. On-line smiles: Does gender make a difference in the use of graphic accents? Journal of Computer-Mediated Communication 2.

Yates, S.J. 1996. Oral and written aspects of computer conferencing. In Computermediated Communication: Linguistic, Social and Crosscultural Perspectives, ed. S. C. Herring, (29-46. Philadelphia: John Benjamins.

Yus, F. 2010. Ciberpragmática 2.0: Nuevos Usos del Lenguaje en Internet. Barcelona, Spain: Ariel Letras. 


\section{Appendix: Websites consulted}

Acomplejados 1 www.acomplejados.com.ar/2008/12

Acomplejados 2 http://www.acomplejados.com.ar/2007/03/24/no-puedo-dejar-a-minovia/

Acomplejados 3 http://www.acomplejados.com.ar/2009/01/10/no-amo-a-mi-noviaquiero-dejarla/

EnFemenino http://foro.enfemenino.com/forum/f101/ f1498_f101-No-se-comodejar-a-mi-novia.html

EnFemenino 2 http://foro.enfemenino.com/forum/pareja1/_f102033_pareja1-Quieroterminar-con-mi-novia-sin-erirla.html

PSICOFXP http://www.psicofxp.com/forums/amor-y-pareja.178/941945-como-lodejo.html

PSICOFXP http://www.psicofxp.com/forums/amor-y-pareja.178/941945-como-lodejo.html

Yahoo

Argentina

http://ar.answers.yahoo.com/question/index; ylt=Aj5k486rQC9T.rfMCVMGf5Wp9gt $\therefore$ ylv=3?qid=20090713173418AAygB45

Yahoo Argentina 2

http://ar.answers.yahoo.com/question/index?qid=20061002171601AAG4W2p

Cualquiera http://www.foro-cualquiera.com/tus-problemas/66328-quiero-dejar-mi$\underline{\text { novio-no-se-hacerlo.html }}$

Tus preguntas http://tuspreguntas.misrespuestas.com/preg.php?idPregunta=10399

Yahoo

Mexico

http://mx.answers.yahoo.com/question/index?qid=20060801121625AASypCT

Yahoo Mexico http://mx.answers.yahoo.com/question/index?qid

Vogue España http://foros.vogue.es/viewtopic.php?f=47\&t=152547 